\title{
Association of Celiac Disease With Pembrolizumab
}

\author{
Ashish Sethi ${ }^{1}$, Alexander Helfand ${ }^{2}$, Lame Balikani ${ }^{3}$, Mark Bunker ${ }^{3}$, Gene Finley ${ }^{2}$ \\ 1. Medical Oncology, Allegheny Health Network, Pittsburgh, USA 2. Hematology \& Oncology, Allegheny Health \\ Network, Pittsburgh, USA 3. Pathology, Allegheny Health Network, Pittsburgh, USA
}

Corresponding author: Ashish Sethi, ashishksethi9@gmail.com

\begin{abstract}
Immune checkpoint inhibitors (ICIs) in the recent times have transformed the landscape of the management of many solid tumors. Unfortunately, many immune-related adverse effects are associated with ICIs, which lead to a negative outcome in cancer treatment. We present a case of a 63-year-old female with metastatic adenocarcinoma of unknown origin, who developed celiac disease during the course of treatment with pembrolizumab. Association of celiac disease with this form of immunotherapy has never been documented before.
\end{abstract}

Categories: Internal Medicine, Gastroenterology, Oncology

Keywords: nivolumab, pembrolizumab, celiac disease, immune-related adverse effects, ipilimumab, cancer immunotherapy, immune check point inhibitor colitis, immune check point inhibitor induced celiac disease, glutenfree diet, immune checkpoint inhibitors

\section{Introduction}

Immunotherapy has acquired a significant role in the management of many solid tumors especially nonsmall cell lung cancers (NSCLCs) and melanoma. Pembrolizumab, an immune checkpoint inhibitor (ICI), is a humanized monoclonal antibody directed against programmed death receptor 1(PD-1), which blocks the negative immune regulatory signals of the PD-1 receptor manifested by T cells, B cells, or macrophages [1]. However, as pembrolizumab blocks the immune system checkpoints, it can cause $\mathrm{T}$ cells to attack healthy cells, leading to different autoimmune diseases, which are termed as immune-related adverse events (irAEs). The most common irAEs observed are pneumonitis, colitis, hepatitis, hypophysitis, thyroiditis, and nephritis $[2]$.

We report an unusual presentation of possible association of celiac disease with pembrolizumab, which is also an autoimmune disease. To the best of our knowledge, the occurrence of celiac disease in a patient after pembrolizumab therapy has been rarely documented in the medical literature.

Review began 05/29/2021 Review ended 06/01/2021 Published 06/10/2021

๑) Copyright 2021 Sethi et al. This is an open access article distributed under the terms of the Creative Commons Attribution License CC-BY 4.0., which permits unrestricted use, distribution, and reproduction in any medium, provided the original author and source are credited.

\section{Case Presentation}

A 63-year-old Caucasian female was diagnosed with metastatic adenocarcinoma of unknown primary origin. Computed tomography (CT) scan findings showed mediastinal lymphadenopathy and left hilar adenopathy. Physical examination was positive for left supraclavicular lymphadenopathy. Her medical history included hypertension, hypothyroidism, and left-sided high-grade ductal carcinoma of the breast. She reported smoking cigarettes (one pack per day) for the past 40 years and denied alcohol consumption or other illicit substance use.

Needle core biopsy performed on the left supraclavicular lymph node demonstrated metastatic adenocarcinoma favoring breast as the primary source of origin. The tumor cells from biopsy results were positive for CK7 and E-Cadherin and focally for GATA3 and CDX-2, and were negative for CK5/6, CK20, TTF1, p40, napsin-A, ER, PR, HER2, mammaglobin, and GCDFP-15 immunostains. Further molecular profiling did not reveal atypical driver mutation, but she did have KRAS G12C, STK-11, and a PALB2 mutation, which is considered as germline mutation.

Based on her evaluation and clinical assessment, she was treated with a combination of carboplatin, paclitaxel, and pembrolizumab. After five cycles of therapy, treatment was held because of immunemediated grade 3 colitis that was unresponsive to steroids. The patient presented with complaints of diarrhea without blood, mild diffuse abdomen pain, and weight loss of 10-12 pounds since few months after starting pembrolizumab. Upon evaluation for infliximab for her unresponsive grade 3 colitis, she was found to have a positive QuantiFERON gold test. Hence, prophylactic anti-tubercular treatment with isoniazid (INH) for nine months was started in view of her latent tuberculosis (TB).

In the interim, the patient underwent colonoscopy, which did not reveal any evidence for colitis as she had complaints of persistent chronic diarrhea that was associated with steatorrhea. Later, the patient also 


\section{Cureus}

developed INH-induced hepatitis, and INH was also withdrawn from her treatment plan for latent TB. Subsequently, drug-induced hepatitis was resolved.

Upper gastrointestinal endoscopy with biopsy was then performed due to refractory diarrhea, which was conclusive of evidence for celiac disease (Figures 1-3).

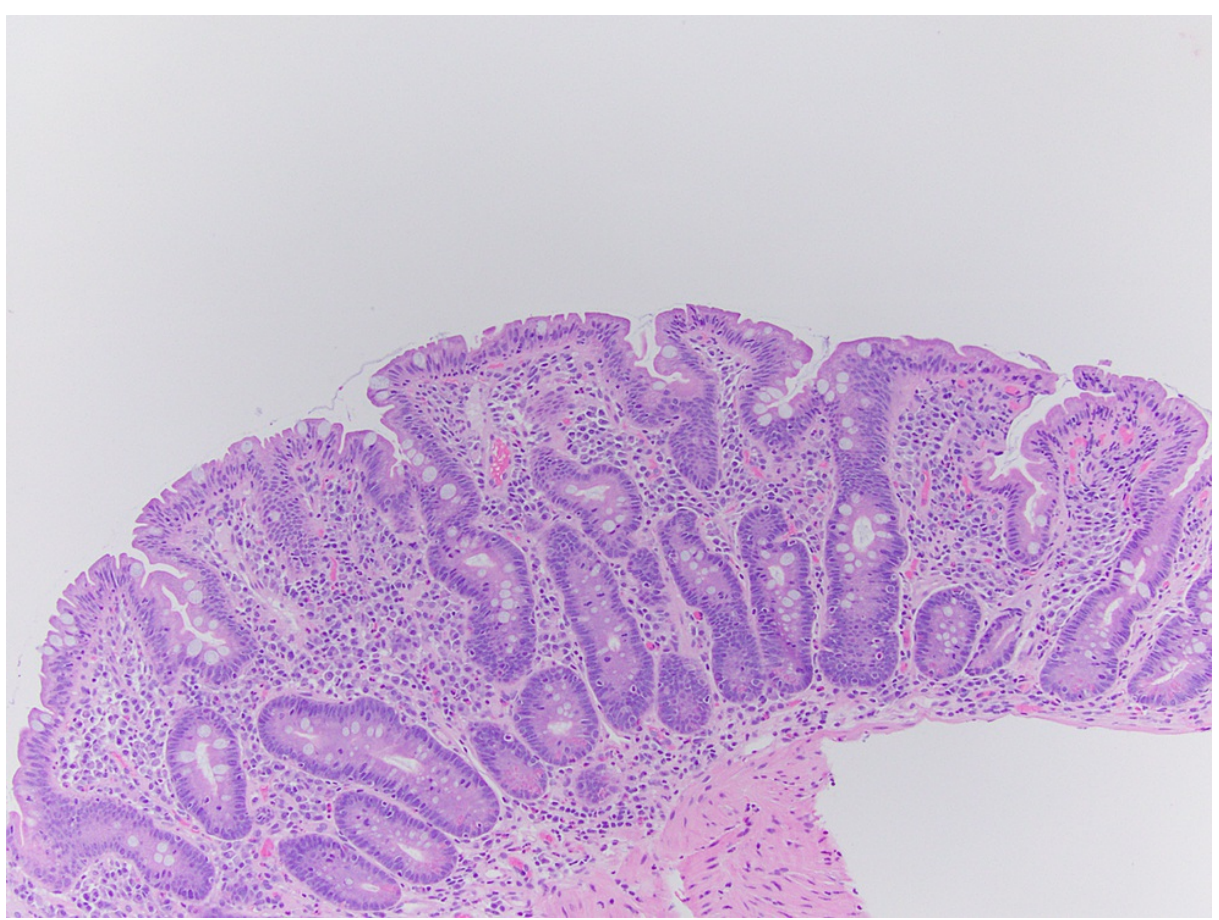

FIGURE 1: Villous blunting crypt hyperplasia (10x)

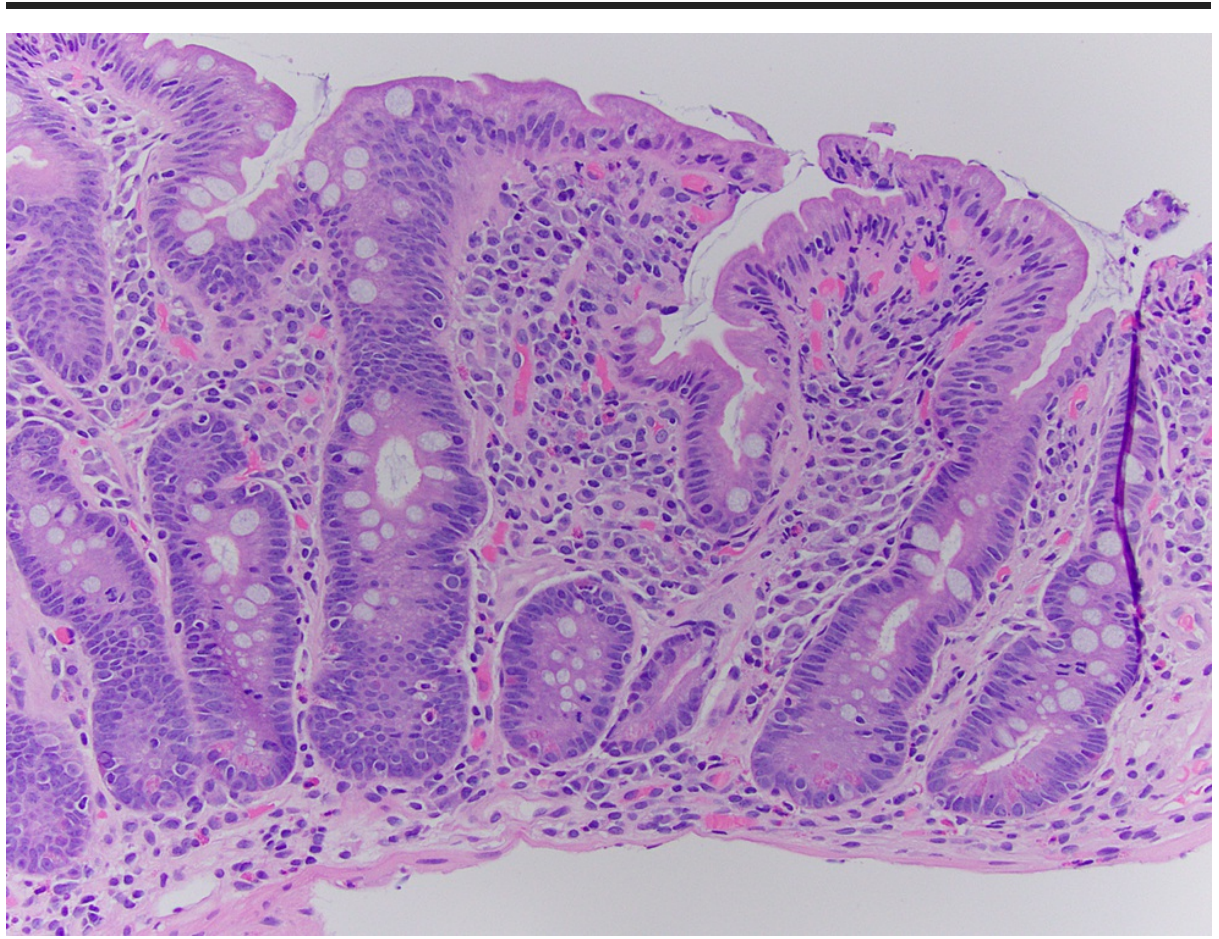

FIGURE 2: Villous blunting crypt hyperplasia (20x) 


\section{Cureus}

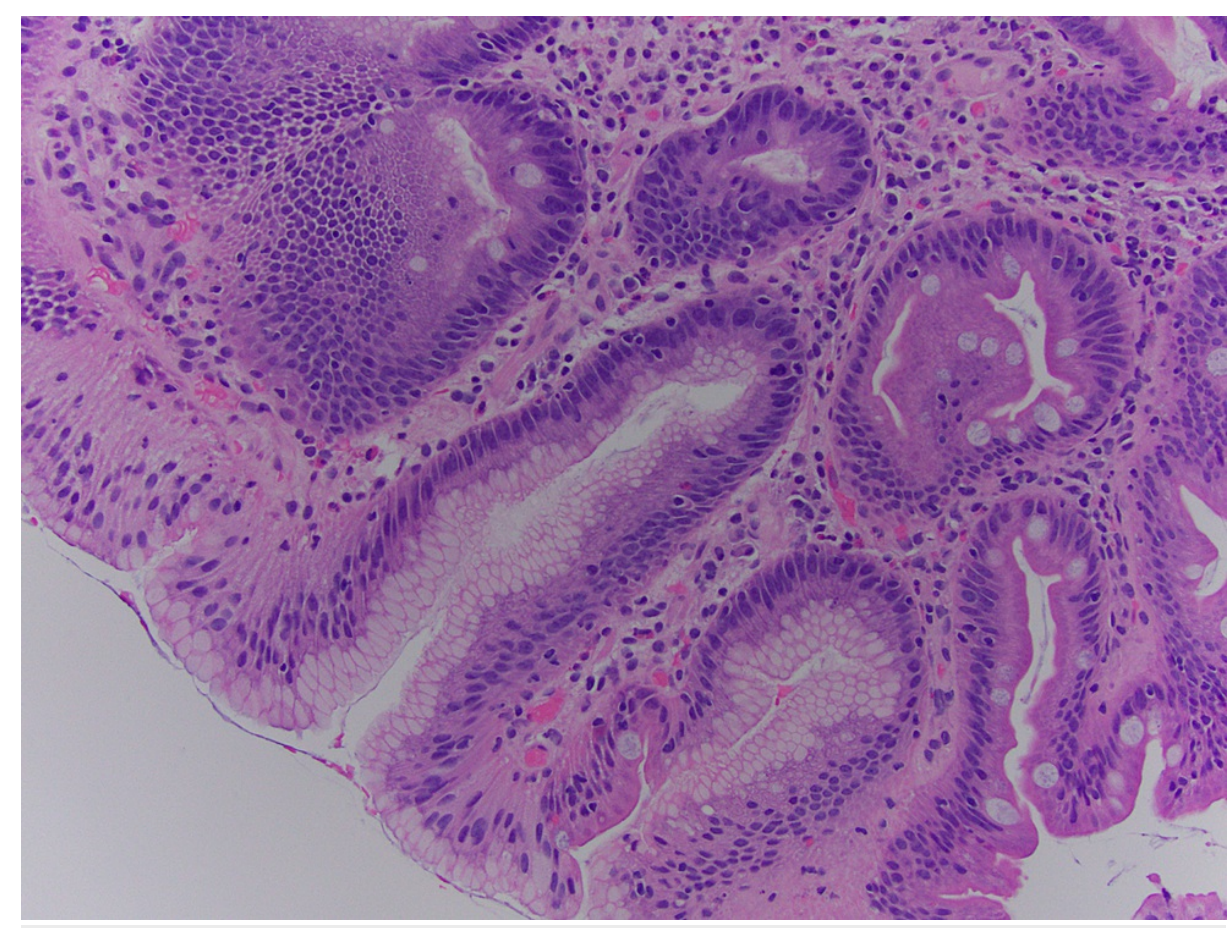

FIGURE 3: Gastric fovelolar metaplasia

Also, important serological tests performed supported the endoscopic findings of celiac disease (Table 1). The patient was managed with strict gluten-free diet after which her diarrhea was resolved.

\begin{tabular}{|l|l|}
\hline Labs & Results \\
\hline Anti-transglutaminase level, IgA & $<2$ \\
\hline Endomysial antibody, IgA & Negative \\
Anti-transglutaminase, IgG & $5 \mathrm{U} / \mathrm{mL}$ \\
Anti-gliadin IgA & $49 \mathrm{U} / \mathrm{mL}$ \\
\hline Anti-gliadin IgG & $41 \mathrm{U} / \mathrm{mL}$ \\
\hline HBsAg & Non-reactive \\
HCV antibody & Non-reactive \\
Hemoglobin & $13.1 \mathrm{~g} / \mathrm{dL}$ \\
WBC & $8,000 \mathrm{k} / \mathrm{mcl}$ \\
\hline
\end{tabular}

\section{TABLE 1: Lab values}

IG, immunoglobulin; HBsAg, hepatitis B surface antigen; HCV, hepatitis C virus; WBC, white blood cell

\section{Discussion}

Many ICIs have been noted to increase overall survival and progression-free survival in different malignancies. Some of the approved immunotherapies currently in use are given in Table 2. 


\section{Cureus}

\begin{tabular}{|c|c|c|}
\hline Immunotherapy & $\begin{array}{l}\text { Target } \\
\text { receptor }\end{array}$ & Indication \\
\hline Pembrolizumab & PD-1 & $\begin{array}{l}\text { Melanoma, NSCLC, squamous cell carcinoma of the head and neck, urothelial carcinoma, gastric } \\
\text { cancer, classic Hodgkin's lymphoma }\end{array}$ \\
\hline Nivolumab & PD-1 & $\begin{array}{l}\text { Melanoma, NSCLC, RCC, HCC, squamous cell carcinoma of the head and neck, urothelial carcinoma, } \\
\text { colorectal cancer with high MSI, classic Hodgkin's lymphoma }\end{array}$ \\
\hline Atezolizumab & PD-L1 & NSCLC, urothelial carcinoma \\
\hline Avelumab & PD-L1 & Merkel cell carcinoma, urothelial carcinoma \\
\hline Durvalumab & PD-L1 & Urothelial carcinoma \\
\hline Ipilimumab & CTLA-4 & Melanoma \\
\hline
\end{tabular}

\section{TABLE 2: Immune checkpoint inhibitors}

CTLA-4, cytotoxic T-lymphocyte-associated protein 4; HCC, hepatocellular carcinoma; MSI, microsatellite instability; NSCLC, non-small cell lung cancer; PD-1, programmed death receptor 1; PD-L1, programmed death-ligand 1; RCC, renal cell carcinoma

irAEs usually develop after few weeks into the treatment with any immunotherapy. However, it may even occur after the cessation of ICIs. Many studies have indicated that with anti-CTLA-4 and anti-PD-1 agents, dermatologic toxicity is seen as an early manifestation [3,4]. As anti-PD-1 or anti-PD-L1 (programmed death-ligand 1) agents are sometimes given for months to years, most studies indicate that prolonged treatment does not result in an increased cumulative incidence of irAEs [5].

Celiac disease is an autoimmune disorder characterized by small intestinal enteropathy that may be diagnosed at any age and affects many organ systems. The classic presentation of celiac disease is diarrhea, which may be accompanied by abdominal pain. However, diarrhea as the main presenting symptom has been noted in less than $50 \%$ of diagnosed cases in the past [6]. Some silent clinical features in celiac disease include iron deficiency anemia, osteoporosis, or incidental recognition at endoscopy performed for other reasons such as gastroesophageal reflux disease [7]. Infrequent clinical signs or symptoms constitute abdominal pain, constipation, weight loss, neurologic symptoms, dermatitis herpetiformis, hypoproteinemia, hypocalcemia, and increased liver enzyme levels [8]. The pathogenesis of celiac disease involves an external trigger (gluten), change in intestinal permeability, human leukocyte antigen (HLA) recognition, and innate and adaptive immune responses to gluten peptides recognizing as self-antigens (e.g., transglutaminase), leading to celiac enteropathy $[9,10]$.

Serum immunoglobulin (Ig) A and IgG anti-tissue transglutaminase antibodies in persons with IgA deficiency are recommended for initial serological testing in celiac disease. IgA antiendomysial antibody level is $100 \%$ specific for active celiac disease [11]. Measurement of deamidated gliadin peptide antibodies of the IgG class has also been introduced as an alternative test and is reported to have better sensitivity and specificity compared to levels of IgG anti-tissue transglutaminase antibodies as a screening tool for celiac disease in IgA deficient individuals [12].

Gluten-free diet is the main treatment for celiac disease, which keeps the disease under remission. Dietary nonadherence to gluten-free diet has been the cause of persistent symptoms of diarrhea and abdominal pain in many cases. Long-term sequelaes of untreated celiac disease can lead to small intestinal adenocarcinoma, refractory sprue, and enteropathy-associated T-cell lymphoma. The response to a gluten-free diet is variable. Approximately $70 \%$ of patients show clinical improvement within two weeks [13].

Badran et al. in their study identified patients who developed ICI-induced celiac disease [14]. Among the patients who developed celiac disease with the ICIs, two had NSCLC, one had extraskeletal myxoid chondrosarcoma, and one had squamous cell carcinoma of the tonsil [14]. Furthermore, the responsiveness of ICI-induced celiac disease to gluten-free diet alone in five (62\%) out of the eight cases illustrated that gluten is an important antigen driving ICI-induced celiac disease, similar to standard celiac disease [14]. Also, Gentile et al. observed ipilimumab-associated celiac disease in a patient with castration-resistant metastatic prostate cancer, who presented with refractory diarrhea after three doses of this or of immunotherapy [15].

A gluten-free diet is a reasonable treatment strategy for patients with ICI-induced celiac disease. Thus, tailoring proper therapy can avoid systemic immune suppression preventing unnecessary discontinuation of ICI treatment. Thus, suspecting ICI-induced celiac disease early in presentation can have substantial clinical implications for many physicians. Esophagogastroduodenoscopy alongside a flexible sigmoidoscopy or 
colonoscopy for the evaluation of immunotherapy-induced colitis should be included as a part of normal routine evaluation.

\section{Conclusions}

ICI-induced celiac disease resembles ICI-induced colitis clinically and histologically but shares the serological features and response to gluten-free diet with the classic celiac disease. We conclude that celiac disease due to immunotherapies is biologically similar to ICI-induced colitis and is likely a variant of ICIinduced colitis or duodenitis. However, the treatment strategies in both forms of entities differ, with ICIinduced celiac disease often improving with gluten-free diet alone, whereas ICI-induced colitis or duodenitis needs systemic immunosuppression.

\section{Additional Information \\ Disclosures}

Human subjects: Consent was obtained or waived by all participants in this study. Conflicts of interest: In compliance with the ICMJE uniform disclosure form, all authors declare the following: Payment/services info: All authors have declared that no financial support was received from any organization for the submitted work. Financial relationships: All authors have declared that they have no financial relationships at present or within the previous three years with any organizations that might have an interest in the submitted work. Other relationships: All authors have declared that there are no other relationships or activities that could appear to have influenced the submitted work.

\section{Acknowledgements}

The completion of this undertaking could not have been possible without the participation and assistance of so many people whose names may not all be enumerated. Their contributions are sincerely appreciated and gratefully acknowledged. To all relatives, friends, and others who in one way or another shared their support, either morally, financially, and physically, thank you.

\section{References}

1. Hamid O, Robert C, Daud A, et al.: Safety and tumor responses with lambrolizumab (anti-PD-1) in melanoma. N Engl J Med. 2013, 369:134-44. 10.1056/NEJMoa1305133

2. Chan MM, Kefford RF, Carlino M, Clements A, Manolios N: Arthritis and tenosynovitis associated with the anti-PD1 antibody pembrolizumab in metastatic melanoma. J Immunother. 2015, 38:37-9. 10.1097/CJI.0000000000000060

3. Weber JS, Hodi FS, Wolchok JD, et al.: Safety profile of nivolumab monotherapy: a pooled analysis of patients with advanced melanoma. J Clin Oncol. 2017, 35:785-92. 10.1200/JCO.2015.66.1389

4. Weber JS, Kähler KC, Hauschild A: Management of immune-related adverse events and kinetics of response with ipilimumab. J Clin Oncol. 2012, 30:2691-7. 10.1200/JCO.2012.41.6750

5. Topalian SL, Sznol M, McDermott DF, et al.: Survival, durable tumor remission, and long-term safety in patients with advanced melanoma receiving nivolumab. J Clin Oncol. 2014, 32:1020-30. 10.1200/JCO.2013.53.0105

6. Rampertab SD, Pooran N, Brar P, Singh P, Green PH: Trends in the presentation of celiac disease . Am J Med. 2006, 119:355.e9-14. 10.1016/j.amjmed.2005.08.044

7. Green PH, Shane E, Rotterdam H, Forde KA, Grossbard L: Significance of unsuspected celiac disease detected at endoscopy. Gastrointest Endosc. 2000, 51:60-5. 10.1016/S0016-5107(00)70389-0

8. Green PH: The many faces of celiac disease: clinical presentation of celiac disease in the adult population . Gastroenterology. 2005, 128:S74-8. 10.1053/j.gastro.2005.02.016

9. Jabri B, Sollid LM: Tissue-mediated control of immunopathology in coeliac disease . Nat Rev Immunol. 2009, 9:858-70. 10.1038/nri2670

10. Schuppan D, Junker Y, Barisani D: Celiac disease: from pathogenesis to novel therapies . Gastroenterology. 2009, 137:1912-33. 10.1053/j.gastro.2009.09.008

11. Giersiepen K, Lelgemann M, Stuhldreher N, Ronfani L, Husby S, Koletzko S, Korponay-Szabó IR: Accuracy of diagnostic antibody tests for coeliac disease in children: summary of an evidence report. J Pediatr Gastroenterol Nutr. 2012, 54:229-41. 10.1097/MPG.0b013e318216f2e5

12. Tonutti E, Visentini D, Picierno A, et al.: Diagnostic efficacy of the ELISA test for the detection of deamidated anti-gliadin peptide antibodies in the diagnosis and monitoring of celiac disease. J Clin Lab Anal. 2009, 23:165-71. 10.1002/jcla.20313

13. Pink IJ, Creamer B: Response to a gluten-free diet of patients with the coeliac syndrome . Lancet. 1967, 1:300-4. 10.1016/s0140-6736(67)91238-x

14. Badran YR, Shih A, Leet D, et al.: Immune checkpoint inhibitor-associated celiac disease. J Immunother Cancer. 2020, 8:e000958. 10.1136/jitc-2020-000958

15. Gentile NM, D'Souza A, Fujii LL, Wu TT, Murray JA: Association between ipilimumab and celiac disease . Mayo Clin Proc. 2013, 88:414-7.10.1016/j.mayocp.2013.01.015 